\title{
Laparoscopy as a diagnostic tool in evaluation of female factors in infertility
}

\section{Chaitra Krishna, Prathima S., Savitha Chandraiah, Anitha G. S.*}

\begin{abstract}
Department of Obstetrics and Gynecology, Bangalore Medical College and Research Institute, Bangalore, India
\end{abstract}
Received: 03 January 2017

Accepted: 30 January 2017

\section{*Correspondence:}

Dr. Anitha G. S.,

E-mail: aninaik85@gmail.com

Copyright: (c) the author(s), publisher and licensee Medip Academy. This is an open-access article distributed under the terms of the Creative Commons Attribution Non-Commercial License, which permits unrestricted non-commercial use, distribution, and reproduction in any medium, provided the original work is properly cited.

\begin{abstract}
Background: Infertility leads to considerable personal suffering and disruption of family life. According to United Nations "Reproductive health is a state of complete physical mental and social well-being and not merely the absence of disease or infirmity in all matters relating to the reproductive system and to its functions and processes". The objective of present study was to find out different causes of female infertility with diagnostic laparoscopy and their comparative frequency in primary and secondary infertility.

Methods: It is a prospective study conducted on all infertile women and they underwent diagnostic laparoscopy for primary and secondary infertility during the study period. Couples who had not lived together for at least 12 months, and those with male factor infertility were excluded. Data were collected on a proforma, and analyzed on SPSS package for windows version 10. Frequencies were calculated for laparoscopic findings regarding primary and secondary infertility.

Results: Fifty infertile women underwent laparoscopy during the study period, $35(70 \%)$ had primary infertility while $15(30 \%)$ secondary infertility. $10(28.5 \%)$ patients with primary and $3(20 \%)$ patients with secondary infertility had no visible abnormality. The common finding was tubal blockage in $10(28.5 \%)$ and $5(33.3 \%)$ cases of primary and secondary infertility respectively. $9(25.7 \%)$ cases of primary infertility were detected as polycystic ovaries (PCO) and $2(13.3 \%)$ in cases of secondary infertility. Endometriosis was found in 1 case with primary infertility and 2 $(13.3 \%)$ cases with secondary infertility. Fibroid was found in $3(8.57 \%)$ and $1(6.6 \%)$ cases of primary and secondary infertility respectively.

Conclusions: Most common causes responsible for infertility were tubal occlusion and polycystic ovary. Infertile couple should be thoroughly investigated. Laparoscopy in infertility can be used for a definitive diagnosis.
\end{abstract}

Keywords: Laparoscopy, Primary infertility, Secondary infertility

\section{INTRODUCTION}

Infertility leads to considerable personal suffering and disruption of family life. According to United Nations "reproductive health is a state of complete physical mental and social well-being and not merely the absence of disease or infirmity in all matters relating to the reproductive system and to its functions and processes". ${ }^{1}$ Infertility is a problem of global proportions, worldwide more than 70 million couples suffer from infertility. ${ }^{2}$ The current evidence indicates $9 \%$ prevalence of infertility (of
12 months) with $56 \%$ couples seeking medical care in more developed and $51.2 \%$ in less developed countries. ${ }^{3}$ Female factors of infertility were more common $(57.5 \%)$ in central part of India. ${ }^{4}$ In India the prevalence of infertility is reported as $21.9 \% .^{5}$ The common factors responsible for infertility in females are anovulatory disorder, tubal factors, endometriosis, uterine and cervical factors. ${ }^{6}$ An accurate diagnosis is the key to successful treatment. The workup of the female partner begins with history and examination. It is more important to perform the relevant investigation in a logical order at 
the correct time than to perform a series of tests as a routine. Simple, least invasive and most predictive investigations should be performed first. Diagnostic laparoscopy is generally not a part of initial infertility evaluation; however, number of reports have shown that it is effective procedure for evaluation of long- term infertility. ${ }^{7,8}$ Laparoscopy provides information regarding tubal and ovarian status, uterine normality and standard means of diagnosing various pelvic pathology e.g. pelvic inflammatory disease, endometriosis, pelvic congestion and tuberculosis. ${ }^{9,10}$ Beside this it is the most useful method of assessment of the tubal patency. After normal hysterosalpingography, laparoscopy reveals abnormal findings in $21.68 \%$ cases of infertile couples. ${ }^{11}$ Untreated pelvic inflammatory disease, post-abortal, postpartum infection and tuberculosis are common factors of infertility in developing countries. ${ }^{12}$ This study was carried out to determine the different causes of female infertility, and their comparative frequency in patients with primary and secondary infertility on diagnostic laparoscopy at the study centre.

\section{METHODS}

This prospective study was conducted in the department of Obstetrics and Gynaecology, Bangalore medical college and research institute, Bangalore, India from October 2015 to October 2016 after approval from the human ethical committee of our institute. Fifty (50) infertile patients attended the gynaecology department of our institute from October 2015 to October 2016. Fifty cases of infertility (primary and secondary) were selected for diagnostic laparoscopy. All the women who failed to conceive after 12 months of regular intercourse, were included. Couples who had not lived together for at least 12 months, those with male factor infertility, and patients with absolute or relative contraindication for laparoscopy i.e. any pre-existing cardiovascular or respiratory condition, generalized peritonitis, intestinal ileus or obstruction and abdominal hernia, were excluded.

Proper informed written consent was taken from every patient. All the patients were admitted in the ward one day prior to procedure. Before the procedure, apart from complete history and detailed examination, baseline investigations (complete blood count, blood sugar, kidney and liver function tests, ECG, chest X-ray) were performed as per our institutional protocol for preanaesthesia check-up. Laparoscopy was done in proliferative phase of menstrual cycle. To test the patency of tubes, chromotubation was done in all cases under laparoscopic vision by using 10-15 $\mathrm{ml}$ of autoclaved methylene blue dye. During the procedure, the pelvis was inspected, including uterus, fallopian tubes, round ligaments, uterovesical pouch, uterosacral ligaments, and Pouch of Douglas. The tubes were inspected for any abnormality in their length and shape. Both ovaries were examined regarding their size, shape, thickness of peripheral follicles, evidence of ovulation. All the data was collected on pre-designed proforma and the results were tabulated and raw percentages calculated to describe the results. For demographic parameters of patients including age, duration of infertility mean, and frequencies were calculated for symptoms and laparoscopic findings regarding primary and secondary infertility.

\section{RESULTS}

The ratio of primary and secondary infertility was 7:3. Out of 50 patients, 35 patients $(70 \%)$ presented with primary infertility and 15 patients $(30 \%)$ presented with secondary infertility. The mean age of presentation was 21-25 years in primary infertility and 26-30 years in secondary infertility (Table 1). Majority of patients had an average married life of 5-10 years in both primary and secondary infertility in this study.

Table 1: Demographic characteristics.

\begin{tabular}{|l|l|l|l|l|}
\hline $\begin{array}{l}\text { Characteri- } \\
\text { stics }\end{array}$ & \multicolumn{3}{l}{$\begin{array}{l}\text { Primary } \\
\text { infertility }\end{array}$} & \multicolumn{2}{l}{$\begin{array}{l}\text { Secondary } \\
\text { infertility }\end{array}$} \\
\hline Age (years) & Number & $\%$ & Number & $\%$ \\
\hline $21-25$ & 12 & 34.5 & 0 & 0 \\
\hline $26-30$ & 10 & 28.5 & 7 & 46.6 \\
\hline $30-35$ & 8 & 22.5 & 4 & 26.6 \\
\hline$>35$ & 5 & 14.3 & 4 & 26.6 \\
\hline Duration of & married life (years) & & \\
\hline$<5$ & 10 & 28.5 & 2 & 13.34 \\
\hline $5-10$ & 20 & 57.1 & 9 & 60 \\
\hline $10-15$ & 5 & 14.3 & 4 & 26.7 \\
\hline
\end{tabular}

Out of 35 patients with primary infertility 15 patients $(42.8 \%)$ had no other symptom. Twenty patients $(57.1 \%)$ presented with various symptoms dysmenorrhoea in 8 patients $(22.8 \%)$, dyspareunia in 8 patients $(22.8 \%), 12$ patients $(34.3 \%)$ had irregular cycles, 10 patients $(28.5 \%)$ presented with excessive weight gain 10 cases $(28.5 \%)$ of hypothyroid. Among the 15 patients with secondary infertility, all patients were symptomatic, dyspareunia was in 7 patients $(46.6 \%)$. Other symptoms like dysmenorrhoea was seen in 7 (46.6\%), 2 patients $(13.3 \%)$ had a history of irregular cycles.6 patients $(40 \%)$ had menorrhagia.

Various causes found in infertility are shown in Table 2. Laparoscopy revealed normal findings in 13 out of 50 patients, $10(28.5 \%)$ patients with primary infertility and 3 patients $(20 \%)$ with secondary infertility. Abnormal findings were present in $37(74 \%)$ patients out of 50 . It was seen that the most common cause observed by laparoscopy was tubal occlusion $(28.5 \%)$ of total, 5 had bilateral tubal block (50\%) 5 had unilateral block $(50 \%)$. This was followed by polycystic ovaries (25.7\%). Chocolate cyst $(2 \%)$ was seen in one patient, uterine anomalies were seen in 2 patients $(5.7 \%)$ and 3 patients $(8.57 \%)$ had fibroid uterus in case of primary infertility while 5 (33.3\%)patients had bilateral tubal block, 2 had uterine anamoly, 2 (13.3\%) chocolate cyst, 2 (13.3\%) polycystic ovaries in cases of secondary infertility. 
Among 50 patients, 10 patients had no any postprocedural complications. Few minor complaints like pyrexia, abdominal discomfort, shoulder pain, vomiting and dry cough were noted in the rest

Table 2: Laparoscopic findings regarding cause of female infertility.

\begin{tabular}{|c|c|c|c|c|c|c|}
\hline \multirow[t]{2}{*}{ Findings } & \multicolumn{2}{|c|}{ Primary infertility } & \multicolumn{2}{|c|}{ Secondary infertility } & \multirow[t]{2}{*}{ Total no. } & \multirow[t]{2}{*}{ Total \% } \\
\hline & Number & $\%$ & Number & $\%$ & & \\
\hline Tubal block & 10 & 28.5 & 5 & 33.3 & 15 & \\
\hline Bilateral block & 5 & 50 & 5 & 33.3 & & \\
\hline Unilateral block & 5 & 50 & 0 & & & \\
\hline Uterine anomaly & 2 & 5.7 & 2 & 13.3 & 4 & 8 \\
\hline Chocolate cyst & 1 & 2 & 2 & 13.3 & 3 & 6 \\
\hline PCOS & 9 & 25.7 & 2 & 13.3 & 11 & 22 \\
\hline Fibroid uterus & 3 & 8.57 & 1 & 6.6 & 4 & 8 \\
\hline Normal study & 10 & 28.5 & 3 & 20 & 13 & 26 \\
\hline
\end{tabular}

\section{DISCUSSION}

Laparoscopy is a mandatory procedure for full assessment of the infertile couple. Statistics regarding infertility in general population are difficult to overcome by since $40 \%$ of infertile couples do not attend a hospital or clinic for treatment illustrating potential for error in hospital based statistics. ${ }^{13}$ Female age is the single most important determinant of spontaneous as well as treatment -related conception. While there is no universally accepted definition of advanced reproductive age, 35 years is considered as the limit in fertility terms (Amrican Soicety of Reproductive Medicine 2006). ${ }^{14}$ In this study $(14.3 \%) 5$ patients presenting with primary infertility and (26.6\%) 4 patients presenting with secondary infertility were of age i.e. $>35$ years. NICE recommendation states that women over 35 years of age should be referred early from primary care for investigation and treatment. There is corresponding rise in mean age at which women present with infertility. In the present study, the mean age at presentation was 21-25 years in primary infertility and $26-30$ years in secondary infertility.

The duration of infertility was 5-10 years in majority of patients $(57.1 \%)$ of primary infertility, while it was over 5 years in majority of patients $(60 \%)$ with secondary infertility. Similar results reported from Lahore i.e. $58 \%$ of patients had primary infertility of 2-5 years while $71 \%$ of patients had infertility of over 5 years. ${ }^{15}$ Major symptoms in the present study were pelvic pain, dyspareunia, and irregular cycles which are in accordance with other infertility studies at national and international level. These symptoms were found to be frequently associated with organic pelvic pathology. The diagnostic laparoscopy should be considered early in symptomatic patients during infertility workup. ${ }^{16}$

In this study, normal pelvic findings and patent tubes on laparoscope was found in $28.5 \%$ cases of primary infertility and only $20 \%$ cases in secondary infertility. The most commonly found pathologies were tubal blockage, polycystic ovarian disease, endometriosis, uterine anomalies, fibroid uterus. Among ovulatory disorders polycystic ovarian disease was the commonest endocrine disorder associated with anovulation. The prevalence of polycystic ovarian disease (PCO) in asymptomatic women is thought to be between 16 and $33 \% .{ }^{17}$ In the present study the incidence of polycystic ovarian disease was $25.7 \%$ in case of primary infertility and $13.3 \%$ was found in cases of secondary infertility. Endometriosis may lead to female infertility, although it has not been confirmed whether endometriosis can be the sole cause of infertility or it is only contributory factor that leads to it. Nevertheless, most women who are infertile suffer from endometriosis. The clinical signs and symptoms that make on of endometriosis (dysmenorrhoea, dyspareunia, abnormal uterine bleeding, chronic pelvic pain and/or pelvic mass, utero-sacral ligament nodularity) are not reliable enough to justify diagnosis and treatment. Current thinking dictates visual and/or microscopic confirmation through laparoscope before diagnosing or treating a patient for endometriosis. $^{18}$

The study conducted by Mahmood showed incidence of endometriosis in $13.6 \%$ of patients in cases of primary infertility and $2.52 \%$ in case of secondary infertility, while in present study the frequency of endometriosis in case of primary infertility was $2 \%$ and $13.3 \%$ in case of secondary infertility, and concluded that the presumption that endometriosis is uncommon in Asian women is considered to be erroneous. ${ }^{19}$ The frequency of fibroid in the present study was $8 \%$ in all cases of infertility, similar results reported by Khaula from Lahore. The incidence of myoma in women with infertility without any obvious cause of infertility is estimated to be $1-2.4 \% .^{20}$ Tubal disease accounts for $15-20 \%$ of cases of primary infertility and approximately $40 \%$ of secondary infertility. ${ }^{21}$ In the present study, the frequency of tubal 
occlusion was 28.5 and $33.33 \%$ in cases of primary and secondary infertility respectively. It represents the aftermaths of pelvic infection or surgery. A single episode of PID carries up to $10 \%$ risk of future tubal factor infertility. ${ }^{22}$ In present study, the frequency of pelvic inflammatory disease (PID) was 8\%. Tubal occlusion and peritubal or periovarian adhesions are factors responsible for inhibition of ovum pickup and transport. Laparoscopy is thus a definitive way to diagnose them. In India, most of patients usually go to alternative medicine and un-trained health practitioners for the treatment of infertility, which leads to further delay in proper management. Laparoscopy not only helps in identification of unsuspected pathology, but also contributes to decision making. It should be considered initially as part of the infertility evaluation in women, especially those with a history of pelvic inflammatory disease, pelvic surgery, and chronic pelvic pain. ${ }^{23}$

\section{CONCLUSION}

Tubal factor was the commonest factor in both types of infertility in the present study next being ovulatory disorders. Laparoscopy should be considered earlier in women with history of PID, pelvic surgery and chronic pelvic pain for effective treatment decisions. Keeping in view the high infertility rates and illiteracy in our region, proper guidance and education of infertile females is needed to consult earlier at proper infertility clinics. Laparoscopy is very effective method in evaluating these infertile women to prevent delay in management.

\section{Funding: No funding sources}

Conflict of interest: None declared

Ethical approval: The study was approved by the Institutional Ethics Committee

\section{REFERENCES}

1. RCOG. The initial investigation and management of the infertile of couple. London: RCOG Press; 1998.

2. Ombelet W, Cooke I, Dyer S, Serour G, Devroey P. Infertility and the provision of infertility medical services in developing countries. Hum Reprod Update. 2008;14:605-21.

3. Boivin J, Bunting L, Collins JA, Nygren KG. International estimates of infertility prevalence and treatment - seeking: potential need and demand for infertility medical care. Hum Reprod. 2007;22:1506-12.

4. Aflatoonian A, Seyedhassani SM, Tabibnejad N. The epidemiological and etiological aspects of infertility in Yazd province of Iran. Iranian $\mathbf{J}$ Reprod Med. 2009;7:117-22.

5. UNFPA. Pakistan population assessment. Islamabad: Government of Pakistan; 2003.

6. Jose Miller AB, Boyden JW, Frey KA. Infertility. Am Fam Physician. 2007;75:849-56.

7. Godinjak Z, Idrizbegovic E. Should diagnostic hysteroscopy be a routine procedure during diagnostic laparoscopy in infertile women? Bosn J Basic Med Sci. 2008;8:44-7.

8. Fartum M, Laufer N, Simon A. Investigations of infertile couple: Should diagnostic laparoscopy be performed after normal hysterosalpingography in treating infertility suspected to be of unknown origin? Hum Reprod. 2002;17:1-3.

9. Mahmood S. An audit of diagnostic laparoscopies for infertility. J Surg Pak. 2003;8:8-10.

10. Sajida P, Majidah K. Role of combined diagnostic laparoscopy and simultaneous diagnostic hysteroscopy for evaluation of female subfertility factors. J Surg Pak. 2010;15:44-7.

11. Tanahatoe SJ, Hompes PG, Lambalk CB. Investigations of infertile couple: should diagnostic laparoscopy be performed in the infertility workup program in patients undergoing intrauterine insemination. Hum Reprod. 2003;18:8-11.

12. Rehana R, Majid SS. Etiological factors of infertility. $\mathbf{J}$ Postgrad Med Inst. 2004;18:166-71.

13. Talib W, Ikram M, Maimoona H, Saeed M. Infertile female; laparoscopic evaluation. Professional Med J 2007; 14:562-6.

14. Maheshwari A, Hamilton M, Bhattacharya S. Effect of female age on the diagnostic categories of infertility. Hum Reprod. 2008;23:538-42.

15. Ashraf V, Baqai SM. Laparoscopy; diagnostic role in infertility. Professional Med J. 2005;12:74-9.

16. Milingos S, Protopapas A, Kallipolitis G, Drakakis P, Makrigiannakis A, Liapi, et al. Laparoscopic evaluation of infertile patients with chronic pelvic pain. Reprod Biomed Online. 2006;12:347-53.

17. Enda McVeigh. Polycystic ovarian syndrome. In: Baker PN, Leusley DM, editors. Obstetric and gynaecology: an evidence based text for Mrocg. London: Oxford University Press; 2004: 588-93.

18. Aziz N. Laparoscopic evaluation of female factors in infertility. J Coll Physicians Surg Pak. 2010;20(10):649-52.

19. Milingos S, Protopapas A, Kallipolitis G, Drakakis P, Makrigiannakis A, Liapi A, et al. Laparoscopic evaluation of infertile patients with chronic pelvic pain. Reprod Biomed Online. 2006;12(3):347-53.

20. Edmonds K, editor. Dewhurst's textbook of obstetrics and gynaecology. 7th ed. India: Blackwell publishing; 2007.

21. Talat N, Lubna H, Gulmeen, Farrah N, Shahida S. Laparoscopic evaluation in infertility. J Coll Physicians Surg Pak. 2009;19:704-7.

22. Khaula K. Role of diagnostic laparoscopy in evaluation of female sub fertility. Serv Inst Med Sci. 2005;3:31-4.

23. Lashen HA. Female infertility. In: Baker PN, Leusley DM, editors. Obstetric and gynaecology: an evidencebased text for Mrocg. London: Oxford University Press; 2004: 566-73.

Cite this article as: Krishna C, Prathima S, Chandraiah S, Anitha GS. Laparoscopy as a diagnostic tool in evaluation of female factors in infertility. Int J Reprod Contracept Obstet Gynecol 2017;6:864-7. 